\title{
CXCR4 expression affects overall survival of HCC patients whereas CXCR7 expression does not
}

\author{
Maria Neve Polimeno ${ }^{1,7}$, Caterina Ierano ${ }^{1,7}$, Crescenzo D’Alterio ${ }^{1}$, Nunzia Simona Losito ${ }^{2}$, \\ Maria Napolitano ${ }^{1}$, Luigi Portella ${ }^{1}$, Giosuè Scognamiglio ${ }^{2}$, Fabiana Tatangelo ${ }^{2}$, Anna Maria Trotta ${ }^{1}$, \\ Steven Curley ${ }^{4}$, Susan Costantini ${ }^{5}$, Raffaele Liuzzi ${ }^{6}$, Francesco Izzo $^{3}$ and Stefania Scala ${ }^{1}$
}

Hepatocellular carcinoma (HCC) is a heterogeneous disease with a poor prognosis and limited markers for predicting patient survival. Because chemokines and chemokine receptors play numerous and integral roles in HCC disease progression, the CXCR4-CXCL12-CXCR7 axis was studied in HCC patients. CXCR4 and CXCR7 expression was analyzed by immunohistochemistry in $86 \mathrm{HCC}$ patients (training cohort) and validated in 42 unrelated HCC patients (validation

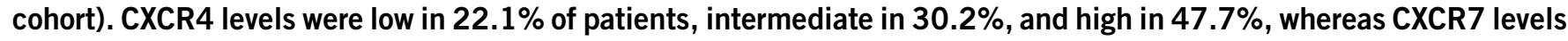
were low in $9.3 \%$ of patients, intermediate in $44.2 \%$ and high in $46.5 \%$ of the patients in the training cohort. When correlated to patient outcome, only CXCR4 affected overall survival $(P=0.03)$. CXCR4-CXCL12-CXCR7 mRNA levels were examined in 33/86 patients. Interestingly, the common CXCR4-CXCR7 ligand CXCL12 was expressed at significantly lower levels in tumor tissues compared to adjacent normal liver $(P=0.032)$. The expression and function of CXCR4 and CXCR7 was also analyzed in several human HCC cell lines. CXCR4 was expressed in Huh7, Hep3B, SNU398, SNU449 and SNU475 cells, whereas CXCR7 was expressed in HepG2, Huh7, SNU449 and SNU475 cells. Huh7, SNU449 and SNU475 cells migrated toward CXCL12, and this migration was inhibited by AMD3100/anti-CXCR4 and by CCX771/anti-CXCR7. Moreover, SNU449 and Huh7 cells exhibited matrix invasion in the presence of CXCL12 and CXCL11, a ligand exclusive to CXCR7. In conclusion, CXCR4 affects the prognosis of HCC patients but CXCR7 does not. Therefore, the CXCR4-CXCL12-CXCR7 axis plays a role in the interaction of HCC with the surrounding normal tissue and represents a suitable therapeutic target.

Cellular \& Molecular Immunology (2015) 12, 474-482; doi:10.1038/cmi.2014.102; published online 3 November 2014

Keywords: CXCR4; CXCR7; CXCL12; hepatocellular carcinoma; prognosis

\section{INTRODUCTION}

Hepatocellular carcinoma (HCC) is a major health problem worldwide and is the third most common cause of cancerrelated death. ${ }^{1}$ Hepatitis $\mathrm{B}$ virus and hepatitis $\mathrm{C}$ virus infection are the most important HCC risk factors; chronic liver injury is typically associated with increased remodeling activity, a massive leukocyte infiltration and non-resolving inflammation. ${ }^{2}$ The migration of leukocytes from the blood into the liver during homeostasis and liver injury is mainly controlled by chemokines, a family of small chemotactic cytokines. ${ }^{3}$ Among them, CXCL12 and the receptor CXCR4 have received the most attention, although the role of these proteins in the context of HCC tumorigenesis and progression is still controversial. ${ }^{4-7}$ Nevertheless, Xiang et al. ${ }^{8}$ have shown that CXCR4 expression significantly decreases overall median survival and is predictive of bone metastasis in HCC patients. Moreover, the nuclear accumulation of CXCR4 is associated with a higher risk of lymph node metastasis in HCC. ${ }^{9}$ Recently, the role of CXCR7 overexpression in the invasion and growth of HCC has been shown. ${ }^{10,11}$ CXCR7 is a newly identified receptor that binds to

\footnotetext{
${ }^{1}$ Oncological Immunology, Istituto Nazionale per lo Studio e la Cura dei Tumori, "Fondazione Giovanni Pascale"-IRCCS-ITALIA, Naples, Italy; ${ }^{2}$ Pathology Unit, Istituto Nazionale per lo Studio e la Cura dei Tumori, "Fondazione Giovanni Pascale"-IRCCS-ITALIA, Naples, Italy; ${ }^{3}$ Hepato-Biliary Surgery Unit, Istituto Nazionale per lo Studio e la Cura dei Tumori, "Fondazione Giovanni Pascale"-IRCCS-ITALIA, Naples, Italy; ${ }^{4}$ Department of Surgical Oncology, University of Texas MD Anderson Cancer Center, Houston, TX, USA; ${ }^{5}$ CROM-Centro Ricerche Oncologiche Mercogliano, Mercogliano (AV), Italy and ${ }^{6}$ Institute of Biostructure and Bioimaging (IBB) of the Italian National Research Council, Naples, Italy

${ }^{7}$ These two authors contributed equally to this work.

Correspondence: Dr S Scala, Oncological Immunology, Istituto Nazionale per lo Studio e la Cura dei Tumori, "Fondazione Giovanni Pascale"-IRCCS-ITALIA, Via M. Semmola 52, 80131 Naples, Italy.

E-mail: scalaste@gmail.com; s.scala@istitutotumori.na.it
}

Received: 22 April 2014; Revised: 22 August 2014; Accepted: 17 September 2014 
CXCL12 $2^{12}$ and was identified in lung and breast tumors, ${ }^{13}$ prostate cancer, ${ }^{14}$ rhabdomyosarcomas ${ }^{15}$ and human glioma. ${ }^{16}$ Whereas the CXCR4 transduction pathway is primarily G-protein mediated, the CXCR7 receptor transduces through the $\beta$ arrestin pathway and is G-protein independent. ${ }^{717-20}$ CXCR7 is implicated in cell growth/survival and adhesion, as well as the promotion of tumor growth, ${ }^{13,20}$ through typical chemokine responses such as chemotaxis, calcium mobilization and the activation of intracellular signaling cascades. ${ }^{21-24}$ Moreover, CXCR7 is implicated in the CXCL12/CXCR4-mediated transendothelial migration of human cancer cells. ${ }^{25}$ However, there are few studies examining CXCR7 expression and its clinical relevance in HCC. Because the coexpression of CXCR4 and CXCR7 has been correlated with metastatic recurrence and a decreased disease-free survival time in non-small lung cancer ${ }^{26}$ and renal cancer ${ }^{27}$ the aim of this work was to evaluate the role of the CXCR4-CXCL12-CXCR7 axis in HCC.

\section{MATERIALS AND METHODS}

\section{Patients}

Liver samples were obtained from 86 patients with HCC who underwent surgical resection from August 2000 to October 2010. Surgically dissected HCC samples were obtained in accordance with the Helsinki Declaration of 1975, with approval from the ethics of Istituto Nazionale per lo Studio e la Cura dei Tumori, 'Fondazione Giovanni Pascale'. Informed consent was obtained from all of the participants in the study according to national guidelines. The etiology of chronic liver disease includes only hepatitis C virus or hepatitis B virus infection. Tissues were fixed in formalin, processed and stained with hematoxylin-eosin to confirm the diagnosis. One paraffin block was chosen from each case for immunohistochemical experiments.

\section{Cell culture}

The human hepatocellular carcinoma cell lines HepG2, Huh7, Hep3B, SNU398, SNU449 and SNU475 were kindly provided by Dr Steven Curley (The University of Texas M.D. Anderson Cancer Center, Houston, TX, USA). The identity of the cell lines were confirmed by the Characterized Cell Line Core Service at M. D. Anderson prior to use in these studies. All of the HCC cell lines were cultured in Dulbecco's modified Eagle medium supplemented with $10 \%$ fetal bovine serum and penicillin/streptomycin and were maintained in $5 \% \mathrm{CO}_{2}$ at $37{ }^{\circ} \mathrm{C}$.

\section{Immunohistochemistry and immunocytochemistry}

CXCR4, CXCR7 and CXCL12 detection was performed by incubating HCC and liver tissue sections with the following primary antibodies: anti-CXCR4 (MAB172, clone 44716; R\&D Systems, Inc., Minneapolis, MN, USA) optimized at a dilution of $1: 1000(1 \mathrm{~h}$, room temperature); anti-CXCR7 (MAB42273, clone 11G8; R\&D Systems, Inc.) optimized at a dilution of 1:50 (overnight, $4{ }^{\circ} \mathrm{C}$ ) and CXCL12 (MAB350, clone 79018; R\&D Systems, Inc.) optimized at a dilution of 1:50 (overnight, $4{ }^{\circ} \mathrm{C}$ ). After incubation, the sections were washed with PBS, and a secondary anti-mouse biotinylated antibody was applied. The sections were incubated with the avidin-biotin complex, and the reaction products were visualized by incubation with the diaminobenzidine chromogen. Sections were then counterstained with hematoxylin, dehydrated and mounted. Negative controls were prepared using PBS in lieu of the first antibody in all cases.

HepG2, Huh7, Hep3B, SNU398, SNU449 and SNU475 human HCC cells grown on culture slides (BD Biosciences, San Jose, CA, USA) were fixed in $4 \%$ paraformaldehyde for $15 \mathrm{~min}$, and they were then washed three times with PBS. The cells were incubated with anti-CXCR7 antibody $(1: 100$, 11G8; R\&D Systems) for $60 \mathrm{~min}$. CXCR4 and CXCR7 staining was semiquantitatively categorized into three classes based on the number of stained (positive) tumors cells. For CXCR4, the classes were low $(0 \%-20 \%)$, intermediate $(20 \%-50 \%)$ or high $(>50 \%)$; for CXCR7, the classes were low $(<60 \%)$, intermediate $(60 \%-80 \%)$ or high $(>80 \%)$.

\section{Immunoblotting}

The cells were washed twice with ice-cold PBS and were lysed in lysis buffer (50 mM Hepes pH 7.5, $150 \mathrm{mM} \mathrm{NaCl}, 10 \%$ glycerol, $1 \%$ TritonX 100, 1 mM EGTA, and $1.5 \mathrm{mM} \mathrm{MgCl}_{2}$ supplemented with protease and phosphatase inhibitors). The primary antibodies used for these experiments were anti-CXCR4 (ab2074; Abcam, Cambridge, MA, USA) and anti-tubulin (Santa Cruz Biotech, Santa Cruz, CA, USA).

\section{RNA isolation and real-time reverse transcription- polymerase chain reaction (PCR)}

Peritumoral healthy tissue at least $30 \mathrm{~mm}$ from the tumor edge was collected from patients who received surgery for HCC. Total RNA from tumors and adjacent healthy tissue was extracted using the RNeasy Protect Mini kit (Qiagen, Valencia, CA, USA). Total extracted RNA (200 ng) was used for the reverse transcription reaction. Real-time PCR was performed using approximately $10 \mathrm{ng}$ of cDNA in a $25 \mu \mathrm{l} \mathrm{Sybr}$ Green reaction mixture, and an ABI Prism 7000 (Applied Biosystem, Carlsbad, CA, USA) robocycler was used for the amplification. Cycling conditions for the PCR were as follows: initial denaturation $\left(10 \mathrm{~min}\right.$ at $95^{\circ} \mathrm{C}$ ), followed by 40 cycles of denaturation $\left(15 \mathrm{~s}\right.$ at $\left.95{ }^{\circ} \mathrm{C}\right)$ and annealing $\left(1 \mathrm{~min}\right.$ at $\left.60^{\circ} \mathrm{C}\right)$.

The gene-specific primers used for the amplification were as follows:

CXCR4: 5' -TGGGTGGTTGTGTTCCAGTTT-3' (forward) 5'-ATGCAATACCAGGACAGGATGA-3' (reverse) CXCR7: 5'-GATTGCCCGCCTCAGAAC-3' (forward)

5'-GCAGGACGCTTTTGTTGG-3' (reverse) CXCL12: 5' -TGTGGCACTCAGATACCGACT-3' (forward) 5'-CCCACAGAGCCAATCACT-3' (reverse) GUSB: 5'-AGCCAGTTCCTCATCAATGG-3' (forward)

5'-GGTAGTGGCTGGTACGGAAA-3' (reverse)

CXCR4, CXCR7 and CXCL12 mRNA were quantified, and their expression level was compared to GUSB mRNA levels. All of the samples were analyzed in triplicate in the real-time PCR experiments. 
Table 1 Characteristics of patients and tumors according to CXCR4 and CXCR7 expression

\begin{tabular}{|c|c|c|c|c|c|c|c|c|c|}
\hline & \multirow{2}{*}{ No. (\%) } & \multicolumn{3}{|c|}{ CXCR4 } & \multirow{2}{*}{$P$} & \multicolumn{3}{|c|}{ CXCR7 } & \multirow{2}{*}{$P$} \\
\hline & & $\begin{array}{c}\text { Low }(0 \%- \\
20 \%)\end{array}$ & $\begin{array}{l}\text { Intermediate } \\
(20 \%-50 \%)\end{array}$ & $\begin{array}{c}\text { High } \\
(>50 \%)\end{array}$ & & $\begin{array}{c}\text { Low } \\
(<60 \%)\end{array}$ & $\begin{array}{l}\text { Intermediate } \\
(60 \%-80 \%)\end{array}$ & $\begin{array}{c}\text { High } \\
(>80 \%)\end{array}$ & \\
\hline Age, years & & & & & 0.4640 & & & & 0.6886 \\
\hline$<65$ & $36(41.9)$ & 6 & 13 & 17 & & 3 & 15 & 18 & \\
\hline$\geqslant 65$ & $50(58.1)$ & 13 & 13 & 24 & & 5 & 23 & 22 & \\
\hline Female & $15(17.5)$ & 2 & 6 & 7 & & 0 & 7 & 8 & \\
\hline pT stage (missing $=9$ ) & & & & & 0.0519 & & & & 0.7361 \\
\hline $\mathrm{T} 1$ & $13(16.9)$ & 1 & 7 & 5 & & 1 & 8 & 4 & \\
\hline $\mathrm{T} 2$ & $32(41.6)$ & 5 & 11 & 16 & & 3 & 13 & 16 & \\
\hline T3 & $27(35.1)$ & 9 & 3 & 15 & & 4 & 9 & 14 & \\
\hline Edmondson's grade (missing $=7$ ) & & & & & 0.2075 & & & & 0.7113 \\
\hline $\operatorname{Low}(1-2)$ & $55(69.6)$ & 11 & 20 & 24 & & 5 & 24 & 26 & \\
\hline High (3-4) & $24(30.4)$ & 7 & 4 & 13 & & 3 & 9 & 10 & \\
\hline
\end{tabular}

\section{Migration assay}

The migration of HepG2, Hep3B, Huh7, SNU398, SNU449 and SNU475 cells was assayed in 24-well transwell chambers (Corning Inc., Corning, NY, USA) using inserts with an $8-\mu \mathrm{m}$ pore membrane. The membranes were pre-coated with collagen (human collagen type IV) and fibronectin $(10 \mu \mathrm{g} / \mathrm{ml})$. Cells were placed in the upper chamber $\left(2.0 \times 10^{5}\right.$ cells/well $)$ in assay medium (Dulbecco's modified Eagle medium) containing $0.5 \% \mathrm{BSA}$ and were incubated with a CXCR4 inhibitor, AMD3100 (5 $\mu$ M; Sigma, St Louis, MO, USA); with a CXCR7 inhibitor, CCX771 (500 nM, gift from ChemoCentryx, Mountain View, CA, USA); with a specific CXCR4 antagonist, Peptide $\mathrm{R}(5 \mu \mathrm{M})$, developed in our laboratory; with an antiCXCR7 monoclonal antibody, CXCR7/RDC-1 (10 $\mu \mathrm{g} / \mathrm{ml}$, Clone 11G8); or with an anti-CXCR4 monoclonal antibody (10 $\mu \mathrm{g} / \mathrm{ml}$, Clone 12G5; R\&D Systems) for $45-60 \mathrm{~min}$ at $37^{\circ} \mathrm{C}$. Then, CXCL12 or CXCL11 $(100 \mathrm{ng} / \mathrm{ml})$ was added to the lower chamber. After $16 \mathrm{~h}$ at $37^{\circ} \mathrm{C}$, the cells on the upper surface of the filter were removed using a cotton wool swab. The cells were counted in ten different consecutive high-power fields (magnification: $\times 200$ ).

\section{Invasion assay}

The in vitro invasion assay was performed using the Bio-Coat Matrigel invasion assay system (BD Biosciences, San Jose, CA, USA) according to the manufacturer's instructions. Hep3B, Huh7 and Hep3B cells $\left(2 \times 10^{5}\right.$ cells $)$ were suspended in serum-free medium containing $0.5 \%$ BSA and seeded into the Matrigel transwell chambers consisting of polycarbonate membranes with $8-\mu \mathrm{m}$ pores. After pre-incubation with an anti-CXCR4 antibody $(10 \mu \mathrm{g} / \mathrm{ml}$, Clone $12 \mathrm{G} 5 ; \mathrm{R} \& \mathrm{D}$ Systems); an anti-CXCR7 antibody $(10 \mu \mathrm{g} / \mathrm{ml}$, Clone 11G8; R\&D Systems); or a specific CXCR4 antagonist, Peptide R
$(5 \mu \mathrm{M})$, which was developed in our laboratory, for 45-60 minutes at $37^{\circ} \mathrm{C}$. Then, CXCL12 or CXCL11 $(100 \mathrm{ng} / \mathrm{ml})$ was added to the lower chamber. After $16 \mathrm{~h}$ at $37^{\circ} \mathrm{C}$, the cells on the upper surface of the filter were removed using a cotton wool swab. The cells were counted in ten different consecutive high-power fields (magnification: $\times 200$ ). The anti-CXCR7 monoclonal antibody CXCR7/RDC-1 (Clone 11G8) and the anti-CXCR4 monoclonal antibody against human CXCR4 (Clone 12G5) were purchased from R\&D Systems.

\section{Statistical analyses}

Associations between the immunohistochemical scores and the clinical and pathologic variables of the tissue specimens were evaluated with a Chi-squared test. Student's $t$-test was used to compare the means. For both tests, a value of $P<0.05$ was considered statistically significant.

The Kaplan-Meier product limit estimator was used to graph overall survival. Univariate analysis was performed with the log-rank test. Cox proportional hazards regression was used to analyze the effect of several risk factors on survival.

\section{RESULTS}

\section{Patient clinicopathological features}

Eighty-six HCC patients were assessed, and the clinical and pathological features are described in Table 1 . The pT classification was not available for nine of the patients. Of the remaining patients, $13(16.9 \%)$ presented at pT1 $(16.8 \%), 32$ patients at pT2 (41.6\%), 27 at pT3 (35.1\%) and 5 patients at pT4 (6.5\%). Nodule size was categorized as diameter $<5$ or $>5 \mathrm{~cm}$, and Edmondson's grade was classified as low (1-2) or high (3-4). CXCR4 was low in 19/86 patients (22.1\%), intermediate in 26/ $86(30.2 \%)$ and high in $41 / 86(47.7 \%)$. CXCR7 was low only in $8 / 86$ cases $(9.3 \%)$, intermediate in $34 / 86(44.2 \%)$ and high in 

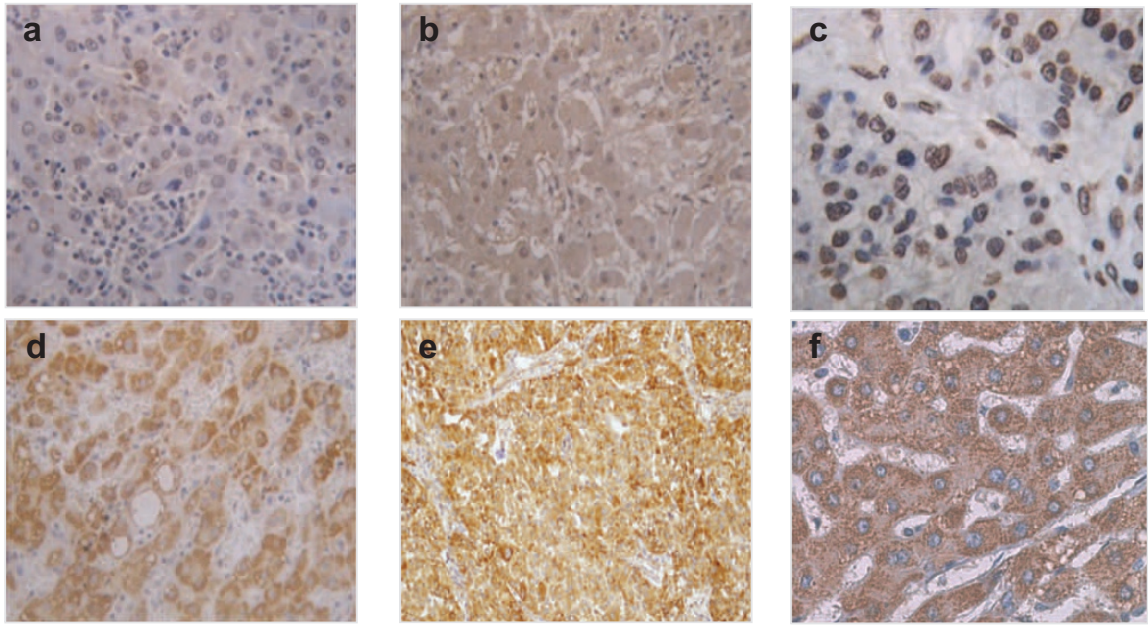

Figure 1 CXCR4 and CXCR7 expression in HCC. (a) CXCR4 expression in the peritumoral area $(\times 20)$. (b) $(\times 20)$, (c) $(\times 40)$. Cytoplasmatic and nuclear CXCR4 staining, respectively, in HCC. (d) CXCR7 expression in the peritumoral area $(\times 20)$. (e) $(\times 20)$, (f) $(\times 40)$. CXCR7 expression in HCC. HCC, hepatocellular carcinoma.

a

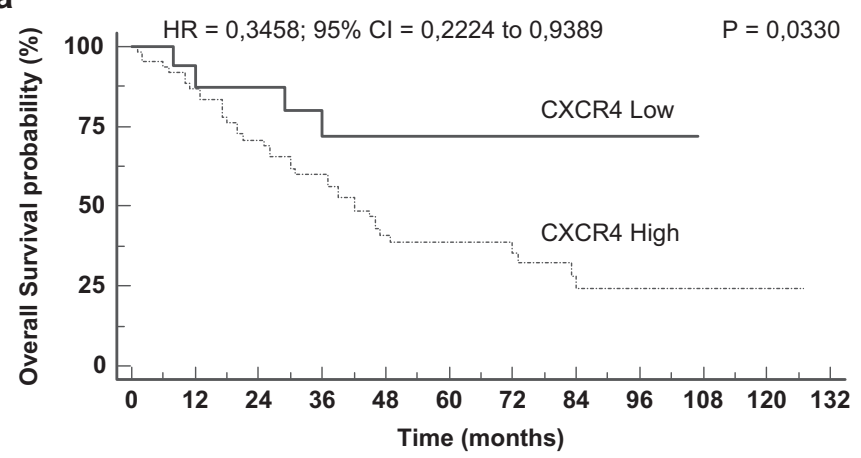

Number at risk

Group: CXCR4 Low

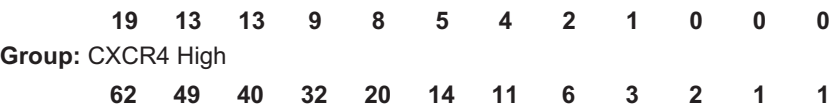

b

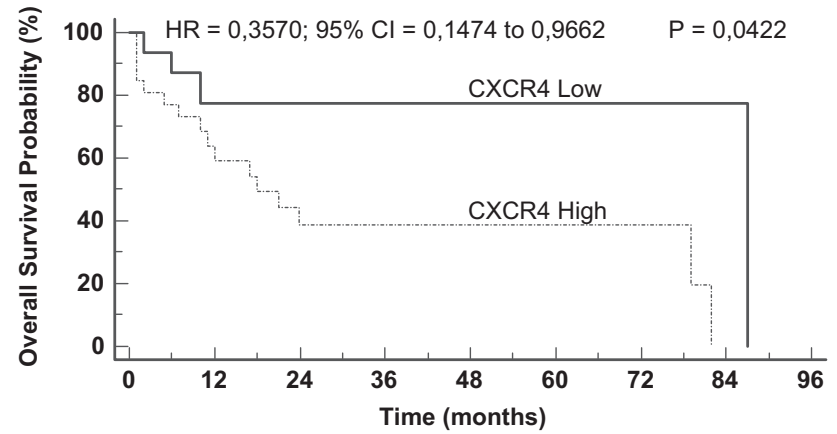

Number at risk

Group: CXCR4 Low

Group: CXCR4 High

2612

5
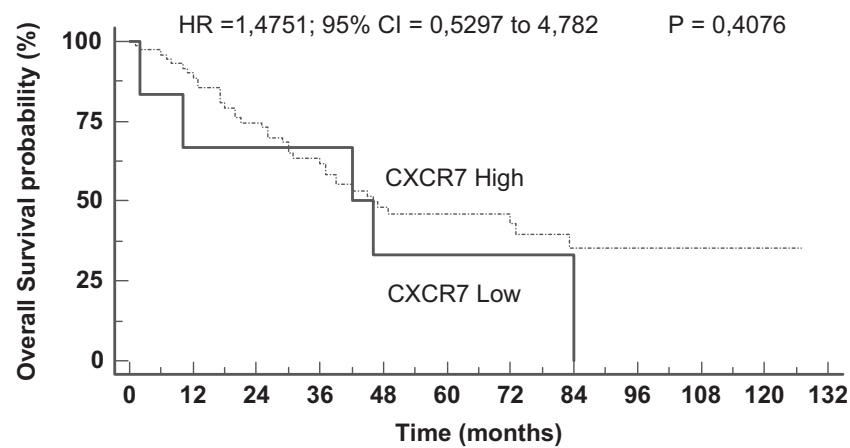

Number at risk

Group: CXCR7 Low
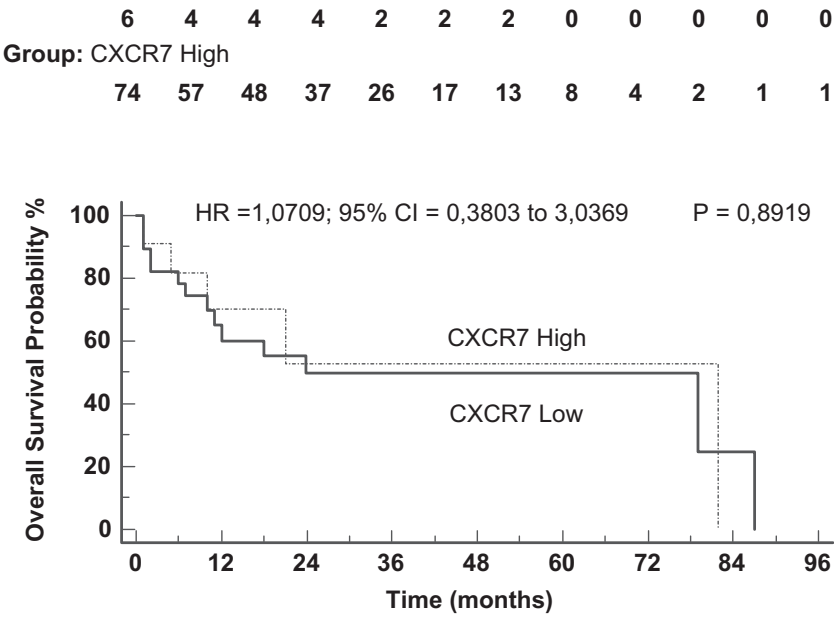

Number at risk

Group: CXCR7 Low

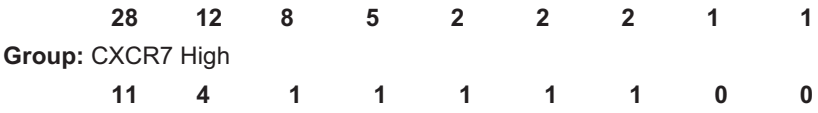

Figure 2 CXCR4 overexpression affects overall survival in HCC patients. (a) Kaplan-Meier curve examining overall survival according to CXCR4 and CXCR7 expression in HCC patients (training cohort). (b) Validation cohort. HCC, hepatocellular carcinoma. 
40/86 (46.5\%). In the peritumoral area, CXCR4 was weakly expressed and localized in the cytoplasm and/or the cell surface, whereas in tumors, CXCR4 was highly expressed and localized to the cytosolic and/or nuclear compartment (Figure 1a-c). CXCR7 showed intense staining in tumors localized in the cytosol (Figure 1d-f). A correlation trend was detected between CXCR4 expression and pT stage $(P=0.0519)$, whereas no correlation was observed between CXCR4 or CXCR7 expression compared to tumor size or Edmondson's grading.

\section{High CXCR4 is correlated with poor overall survival in HCC patients}

To evaluate the prognostic role of CXCR4 and CXCR7 in HCC, the overall survival and progression-free survival were evaluated in $86 \mathrm{HCC}$ patients as a training cohort and in 42 unrelated HCC patients as a validation cohort (Supplementary Table 1). Kaplan-Meier curves based on CXCR4 expression revealed that high CXCR4 expression predicted relatively poor overall survival in both cohorts, whereas CXCR7, which was widely expressed, did not significantly correlate with prognosis (Figure 2).
The CXCR4-CXCR7 ligand CXCL12 was highly expressed in peritumoral tissue in HCC patients

To evaluate if the chemokine receptor levels are due to increased transcription, the mRNA levels of CXCR4, CXCR7 and CXCL12 were evaluated in 33/86 frozen tissues using realtime PCR (Figure 3a). CXCR4 mRNA was upregulated in 15/33 (45.5\%) HCC patients, and CXCR7 expression was increased in $18 / 33(54.5 \%)$ patients. In $23 / 33(69.7 \%)$ HCC patients, CXCR7 was overexpressed compared to CXCR4 (mean fold change 5.5), whereas in 9/33 samples (27.3\%), CXCR4 was upregulated (mean fold change 4.4) compared to CXCR7 levels. Interestingly, the ligand CXCL12 was overexpressed in the tumor tissue in only three cases, although in 30/33 (90.9\%) cases, CXCL12 was overexpressed in peritumoral tissue (mean fold change: 13.5). In Figure 3b, the relative box-plot demonstrates that CXCL12 expression was significantly different between tumor and peritumoral tissues, with lower expression in tumor tissues $(P=0.032)$. CXCL12 was also evaluated using immunohistochemistry, which confirmed a lower expression level in the tumor tissues compared to peritumoral tissues (Figure 3c).

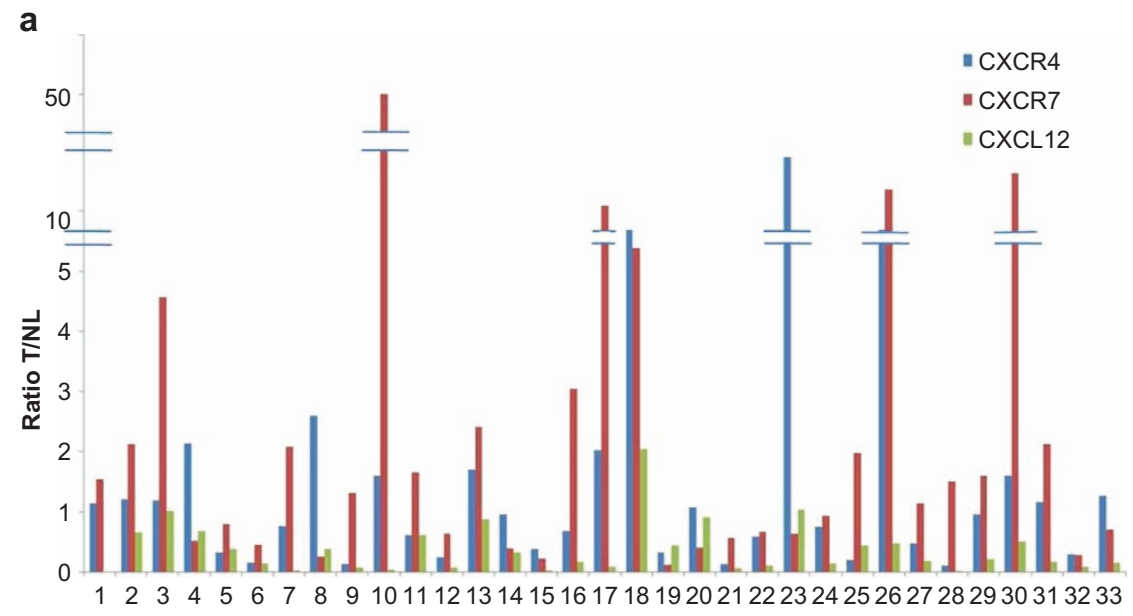

b
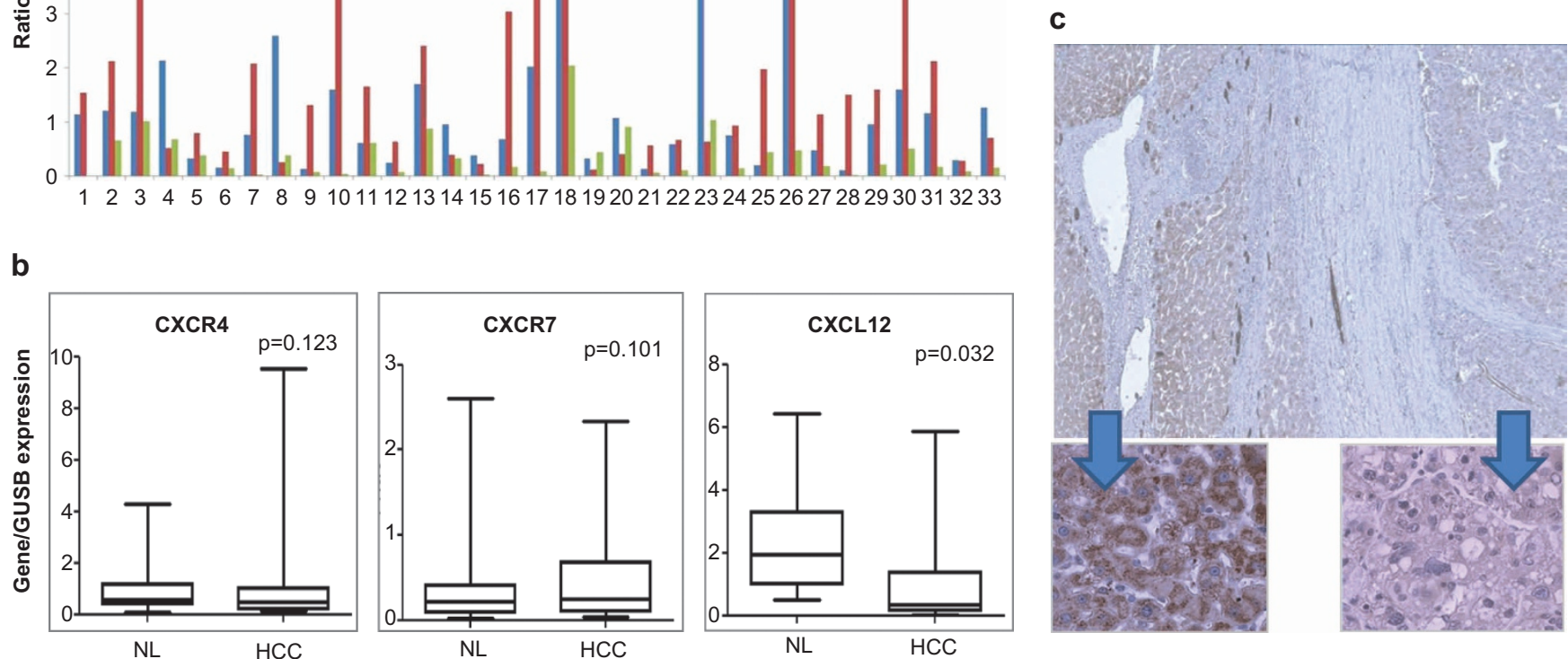

Figure 3 CXCR4, CXCR7 and CXCL12 mRNA expression in HCC. (a) Quantitative reverse transcriptase PCR analysis for CXCR4, CXCR7 and CXCL12 levels in HCC patients. mRNA expression was measured using real-time PCR in normal liver (NL) and HCC. The $y$-axis values represent the ratio between the value of each gene in $\mathrm{HCC}$ /normal liver normalized to GUSB RNA expression. Each assay was performed in triplicate. (b) Relative box plot. (c) Immunohistochemical CXCL12 evaluation. Upper left: peritumoral liver tissue; upper right: HCC tissue (magnification: $\times 5$ ). Lower left: detail peritumoral liver tissue; lower right: detail HCC tissue (magnification: $\times 40$ ). HCC, hepatocellular carcinoma; PCR, polymerase chain reaction. 
a

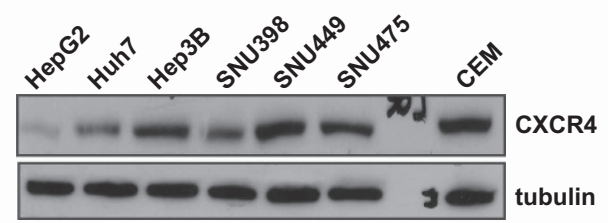

b

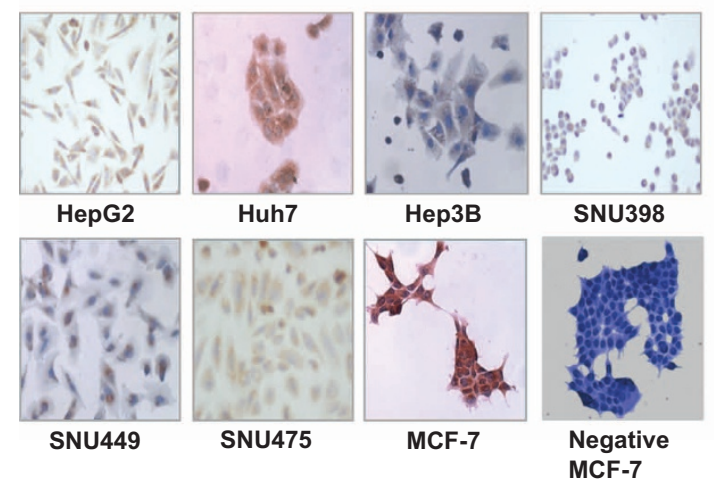

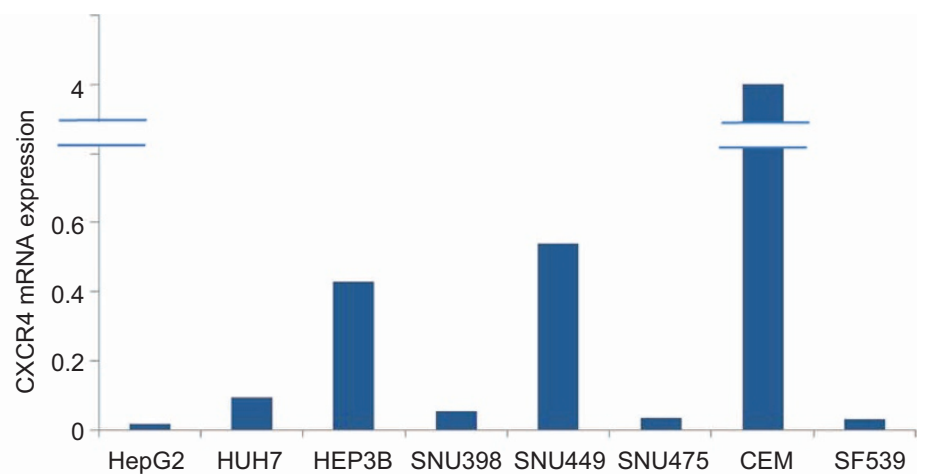

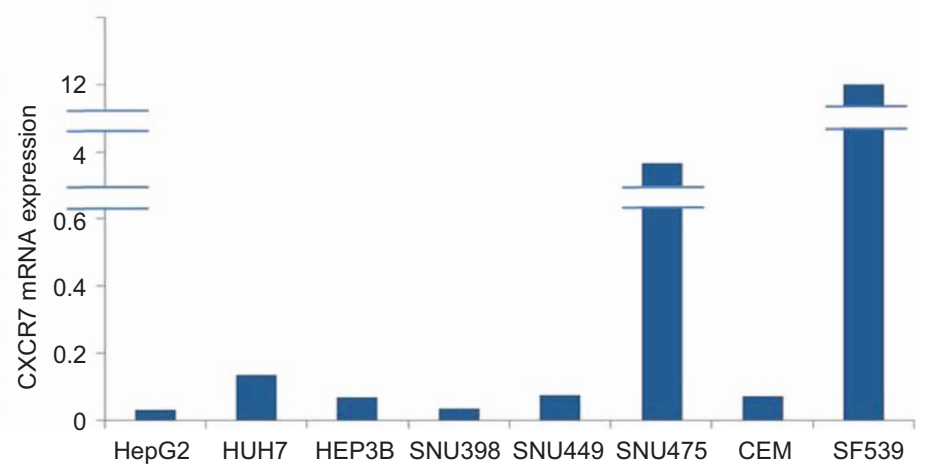

Figure 4 (a) CXCR4 expression in HCC cell lines. Left, western blot analysis for CXCR4 in HCC cell lines. CEM, a human T-lymphoblast cell line, was used as the CXCR4 positive control. Right, CXCR4 mRNA levels as detected by real-time PCR. Representative data from three individual experiments are shown. (b) CXCR7 expression in HCC cell lines. Left, immunocytochemistry for CXCR7 in HCC cell lines. MCF-7, a human breast cancer cell line, was used as the CXCR7 positive control. Right, CXCR7 mRNA level as detected by real-time PCR. SF-539, a human adult cancer brain glioblastoma, was used as a CXCR7 positive control. Representative data from three individual experiments are shown. HCC, hepatocellular carcinoma; PCR, polymerase chain reaction.

\section{CXCR4 and CXCR7 are expressed and functional in HCC cell lines}

To further investigate the function of this chemokine axis in HCC, a panel of human HCC cell lines (HepG2, Huh7, Hep3B, SNU398, SNU449 and SNU475) were characterized for CXCR4 and CXCR7 expression and function. Figure $4 \mathrm{a}$ shows that CXCR4 protein was almost undetectable in HepG2 cells, although it was clearly expressed in Huh7, Hep3B, SNU398, SNU449 and SNU475 cells with an RNA level comparable to the protein level. CXCR7, evaluated using immunocytochemistry, showed that HepG2, Huh7, SNU449 and SNU475 cell lines overexpressed CXCR7 mainly in the cytosol (Figure 4b). CXCL12 significantly induced migration of Huh7, SNU449 and SNU475 cells, whereas migration was significantly inhibited by AMD3100 (CXCR4 antagonist) and by CCX771 (CXCR7 antagonist) in Huh7, SNU449 and SNU475 cells, suggesting a functional role for the CXCR4 and CXCR7 receptors (Figure 5a). CXCL12-dependent migration was not detectable in HepG2, Hep3B or SNU398 cells (data not shown). To further dissect the role of CXCR4 and CXCR7 receptors, the migration of Huh7 and SNU449 cells in response to CXCL12 or CXCL11, the exclusive CXCR7 ligand, was evaluated in the presence of anti-CXCR4 (12G5) $(10 \mu \mathrm{g} / \mathrm{ml})$, anti-CXCR7 (11G8) $(10 \mu \mathrm{g} / \mathrm{ml})$ or Peptide $\mathrm{R}(10 \mu \mathrm{M})$, a recently developed
CXCR4 antagonist. ${ }^{28}$ As shown in Figure 5b, the cells migrated toward CXCL12 and CXCL11. The migration toward CXCL12 was inhibited by anti-CXCR4 and Peptide R, whereas CXCL11induced migration was inhibited by anti-CXCR7, demonstrating that both chemokine receptors affected migration in the evaluated HCC cell lines. To further elucidate the role of CXCR4/CXCR7 in HCC cancer progression, CXCL12/ CXCL11-induced cell invasion experiments were performed in Huh7 and SNU449 cells. As shown in Figure 5c, CXCL12 and CXCL11 significantly stimulated Huh7 and SNU449 invasion, which was impaired by anti-CXCR4 (12G5) and Peptide $\mathrm{R}$ and by anti-CXCR7 (11G8). These results suggest that CXCL12 modulates cell invasion through CXCR4/CXCR7 receptors.

\section{DISCUSSION}

The discovery of the new chemokine receptor CXCR7 and the identification of a functional chemokine axis, CXCR4CXCL12-CXCR7, has led to the examination of a possible role for CXCR7 in HCC. In this manuscript, the chemokine receptors CXCR4 and CXCR7 were evaluated in 86 HCC patients using immunohistochemistry. The expression of intermediate and/or high CXCR4 levels correlated with an unfavorable prognosis for overall survival $(P=0.03)$, whereas CXCR7 expression 

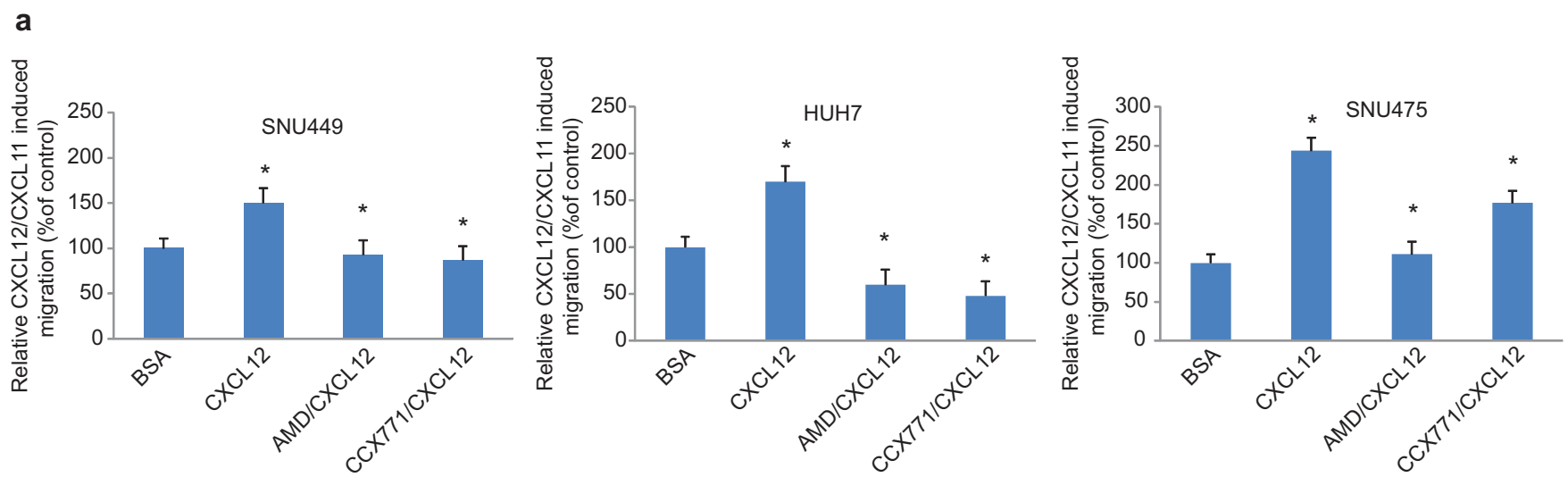

\section{b}
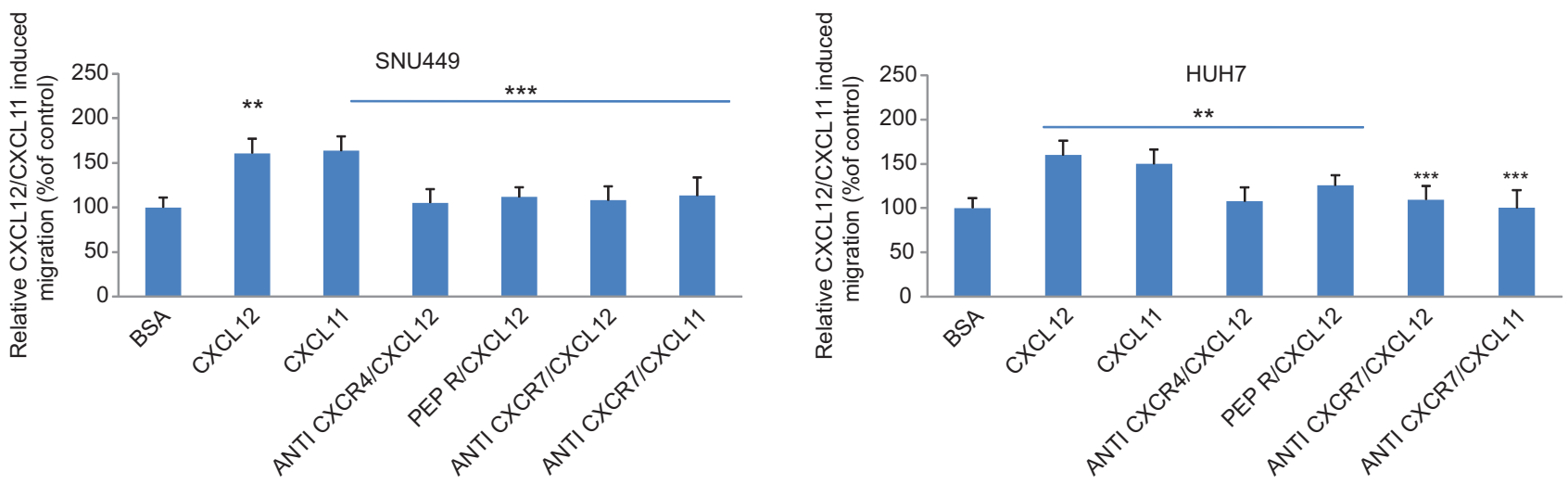

C
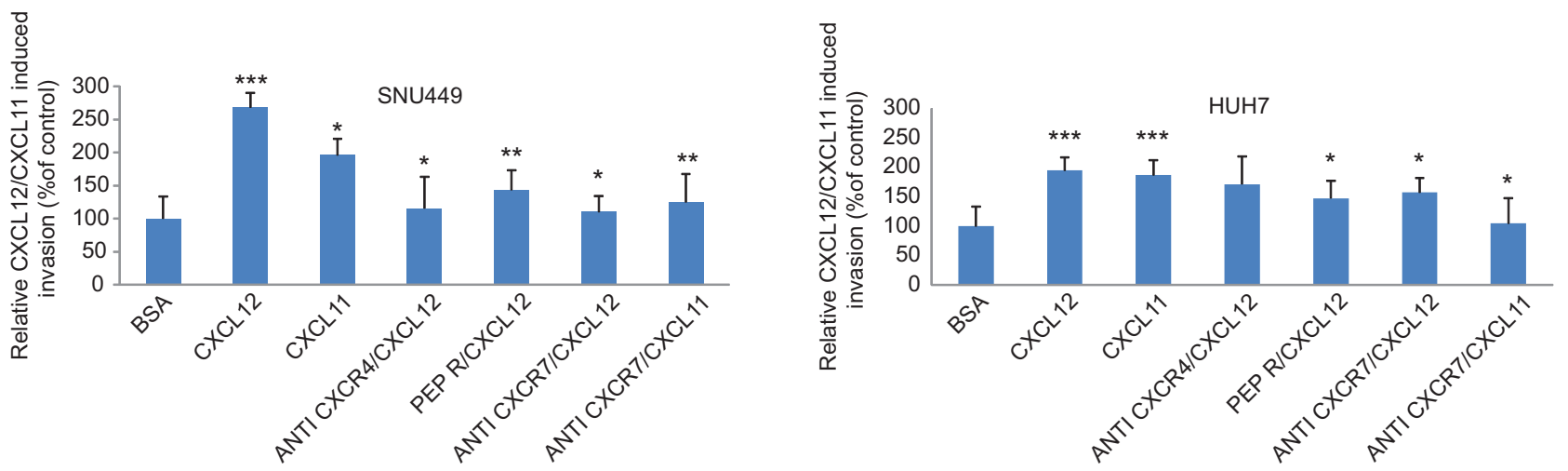

Figure 5 CXCL12 induced migration and invasion in HCC cell lines. (a) Migration of HepG2, Hep3B, Huh7, SNU398, SNU449 and SNU475 cells. The cells were incubated in the presence of Peptide R (10 mM), AMD3100 ( $5 \mu \mathrm{M})$ or CCX771 (500 nM). Cells migrated toward CXCL12 (100 ng/ml) or CXCL11 (100 ng/ml) for $18 \mathrm{~h}$. (b) CXCL12-dependent cell migration was examined in the human HCC cell lines HUH7 and SNU449 in the presence of Peptide R ( $5 \mu \mathrm{M})$, anti-CXCR4 (12G5; $10 \mu \mathrm{g} / \mathrm{ml})$ or anti-CXCR7 (10 $\mu \mathrm{g} / \mathrm{ml})$. The cells migrated toward CXCL12 (100 ng/ml) or CXCL11 (100 ng/ml) for 18 h. (c) CXCL12/CXCL11-dependent cell invasion was examined in the human HCC cell lines Huh7 and SNU449 in the presence of Peptide R ( $5 \mu \mathrm{M})$, anti-CXCR4 (12G5; $10 \mu \mathrm{g} / \mathrm{ml})$ or anti-CXCR7 $(10 \mu \mathrm{g} / \mathrm{ml})$ for $18 \mathrm{~h}$. The cells were counted in 10 different consecutive high-power fields (magnification: $\times 200$ ). The results represent at least three independent experiments and are expressed relative to the values for BSA alone. Statistical significance was calculated using Student's $t$-test. $* P<0.05, * * P<0.001$, ${ }^{* * *} P<0.001$ for BSA and the relative inhibitor. HCC, hepatocellular carcinoma.

was not observed to have prognostic relevance. At the RNA level, the ligand, CXCL12, was significantly overexpressed into the peritumoral tissues $(P=0.032)$, suggesting a potential role for CXCL12 in the microenvironment promoting migration and tumor cell growth. Evaluating the human HCC cell lines
HepG2, Huh7, Hep3B, SNU398, SNU449 and SNU475 for CXCR4 and CXCR7 demonstrated that the receptors are active in HCC cells. It was previously reported that HCC cell lines expressed variable levels of functional CXCR $4,{ }^{7}$ and in this study, a variable correlation between expression and function 
was also detected for CXCR7. In HepG2 cells, CXCR4 was almost undetectable but was associated with clear CXCR7 expression, although no functional migration was observed in the presence of the ligand CXCL12. This could be explained by receptor resistance, as previously described for HepG2, Daudi and Raji lymphoma cells. ${ }^{29-31}$ In Huh7 CXCR7-expressing cells, CXCL12 increased migration, but in Hep3B cells, which expressed both CXCR4 and CXCR7, migration was not induced by CXCL12.

Zheng et al. ${ }^{11}$ described highly variable expression of CXCR4 and CXCR7 in HCC cell lines and demonstrated that CXCR7 silencing in SMMC-7721 cells inhibited cell invasion capability. In agreement with previous results, we observed that CXCR4 localizes to the cytosol of peritumoral tissues and to the cytosol, surface membrane and nucleus of the tumor cells. ${ }^{5,32,33}$ Interestingly, it was previously reported that HCC patients with nuclear CXCR4 and VEGF-C expression displayed higher incidence of lymph node metastases, bone metastases and poor outcome. ${ }^{7,8,9,34}$ The CXCR7 staining was reported to be cytosolic and/or membranous in tumor tissue, ${ }^{11,35}$ which has also been described in tumor endothelial cells of breast, lung, ovary and kidney cancers. ${ }^{13}$ In HCC, CXCR7 and alpha fetoprotein levels were described as valuable prognostic indicators for lung metastasis and poor prognosis. ${ }^{11,34}$ Nevertheless, we were not able to identify any prognostic correlation for CXCR7 expression, possibly because high CXCR7 expression is also regulated by more finely tuned CXCR4-CXCL12 levels. ${ }^{21}$ In fact, at the RNA level, both CXCR4 and CXCR7 chemokine receptors were comparably expressed in tumor and peritumoral tissue, whereas the common ligand CXCL12 was significantly higher in peritumoral tissue $(P=0.032)$. Other researchers have reported that greater CXCR7 expression was induced in HCC compared to normal liver tissue, whereas CXCL12 and CXCR4 were not. ${ }^{10,33}$ Because CXCL12 levels decrease in the tumor, this might favor cell migration toward sites with higher CXCL12 levels, such as lymph nodes and bone. ${ }^{8,9}$ Despite having all of the canonical features of GPCRs, CXCR7-ligand-mediated activation of intracellular signals remains controversial because CXCR7 fails to activate heterotrimeric $\mathrm{G}$ proteins but preferentially recruits $\beta$-arrestin in a ligand-dependent manner. ${ }^{41}$ Interestingly, it has been shown that CXCR7 has a dramatic effect on the signaling response after CXCR4 activation. For example, CXCR7 can directly modulate CXCR4 signals via CXCR7-CXCR4 heterodimerization $^{36}$ and can function as a 'decoy' receptor or chemokine scavenger. ${ }^{37-41}$ Internalization of CXCL11- or CXCL12-bound CXCR7 in the absence of downstream signaling would generate a gradient of chemokine required for an optimum CXCR4 migratory response. ${ }^{41}$

Although more patients need to be evaluated, we identified a biological and prognostic role for the CXCR4-CXCL12CXCR7 axis in HCC patients. This may also be useful in identifying novel targets for therapy to suppress HCC tumorigenesis and progression in patients with chronic hepatitis and liver injury.

\section{ACKNOWLEDGEMENTS}

The authors are indebted to Dr Mark Penfold, Chemocentryx, Mountain View, CA, USA, for kindly providing the CXCR7 inhibitor, CCX771, and to Dr Steven Curley, The University of Texas M.D. Anderson Cancer Center, Houston, TX, USA, for kindly providing the human HCC cell lines. This work was supported by the Grant FIRB $\mathrm{n}$. RBAP11884M and by the Associazione Italiana per la Ricercasul Cancro (AIRC Grant No. 13192).

Supplementary Information accompanies the paper on Cellular \& Molecular Immunology's website (http://www.nature.com/cmi).

1 Jemal A, Siegel R, Ward E, Murray T, Xu J, Thun MJ. Cancer statistics (2007). CA Cancer J Clin 2007; 57: 43-66.

2 Malhi H, Gores GJ. Cellular and molecular mechanisms of liver injury. Gastroenterology 2008; 134: 1641-1654.

3 Wald O, Weiss ID, Galun E, Peled A. Chemokines in hepatitis C virus infection: pathogenesis, prognosis and therapeutics. Cytokine 2007; 39: 50-62.

4 Huang F, Geng XP. Chemokines and hepatocellular carcinoma. World J Gastroenterol 2010; 16: 1832-1836.

5 Li W, Gomez E, Zhang Z. Immunohistochemical expression of stromal cell-derived factor-1 (SDF-1) and CXCR4 ligand receptor system in hepatocellular carcinoma. J Exp Clin Cancer Res 2007; 26: 527533.

6 Liu H, Pan Z, Li A. Roles of chemokine receptor 4 (CXCR4) and chemokine ligand 12 (CXCL12) in metastasis of hepatocellular carcinoma cells. Cell Mol Immunol 2008; 5: 373-378.

7 Schimanski CC, Bahre R, Gockel I. Dissemination of hepatocellular carcinoma is mediated via chemokine receptor CXCR4. Br J Cancer 2006; 95: 210-217.

8 Xiang ZL, Zeng ZC, Tang ZY, Fan J, Zhuang PY, Liang Y et al. Chemokine receptor CXCR4 expression in hepatocellular carcinoma patients increases the risk of bone metastases and poor survival. $B M C$ Cancer 2009; 9: 176.

9 Xiang Z, Zeng Z, Tang Z, Fan J, Sun H, Wu W et al. Increased expression of vascular endothelial growth factor- $C$ and nuclear CXCR4 in hepatocellular carcinoma is correlated with lymph node metastasis and poor outcome. Cancer J 2009; 15: 519-525.

10 Monnier J, Boissan M, L'Helgoualch A. CXCR7 is up-regulated in human and murine hepatocellular carcinoma and is specifically expressed by endothelial cells. Eur J Cancer 2012; 48: 138-148.

11 Zheng K, Li HY, Su XL, Wang XY, Tian T, Li F et al. Chemokine receptor CXCR7 regulates the invasion, angiogenesis and tumor growth of human hepatocellular carcinoma cells. J Exp Clin Cancer Res 2010; 29: 31.

12 Balabanian K, Lagane B, Infantino S. The chemokine SDF-1/CXCL12 binds to and signals through the orphan receptor RDC1 in T lymphocytes. J Biol Chem 2005; 280: 35760-35766.

13 Miao Z, Luker KE, Summers BC CXCR7 (RDC1) promotes breast and lung tumor growth in vivo and is expressed on tumor-associated vasculature. Proc Natl Acad Sci USA 2007; 104: 15735-15740.

14 Wang J, Shiozawa Y, Wang J. The role of CXCR7/RDC1 as a chemokine receptor for CXCL12/SDF-1 in prostate cancer. J Biol Chem 2008; 283: 4283-4294.

15 Tarnowski M, Grymula K, Reca R. Regulation of expression of stromalderived factor- 1 receptors: CXCR 4 and CXCR 7 in human rhabdomyosarcomas. Mol Cancer Res 2010; 8: 1-14.

16 Hattermann K, Held-Feindt J, Lucius R. The chemokine receptor CXCR7 is highly expressed in human glioma cells and mediates antiapoptotic effects. Cancer Res 2010; 70: 3299-3308.

17 Müller A, Homey B, Soto H. Involvement of chemokine receptors in breast cancer metastasis. Nature 2001; 410: 50-56.

18 Murphy PM. The molecular biology of leukocyte chemoattractant receptors. Annu Rev Immunol 1994; 12: 593-633. 
19 Taichman RS, Cooper C, Keller ET, Pienta KJ, Taichman NS, McCauley LK. Use of the stromal cell-derived factor-1/CXCR4 pathway in prostate cancer metastasis to bone. Cancer Res 2002; 62: 1832-1837.

20 Burns JM, Summers BC, Wang Y, Melikian A, Berahovich R, Miao Z et al. A novel chemokine receptor for SDF-1 and I-TAC involved in cell survival, cell adhesion, and tumor development. J Exp Med 2006; 203: 2201-2213.

21 Thelen M, Thelen S. CXCR7, CXCR4 and CXCL12, an eccentric trio? J Neuroimmunol 2008; 198: 9-13.

22 Sierro F, Biben C, Martínez-Muñoz L, Mellado M, Ransohoff RM, Li M et al. Disrupted cardiac development but normal hematopoiesis in mice deficient in the second CXCL12/SDF-1 receptor, CXCR7. Proc Natl Acad Sci USA 2007; 104: 14759-14764.

23 Grymula K, Tarnowski M, Wysoczynski M, Drukala J, Barr FG, Ratajczak J et al. Overlapping and distinct role of CXCR7-SDF-1/ ITAC and CXCR4-SDF-1 axes in regulating metastatic behavior of human rhabdomyosarcomas. Int J Cancer 2010; 127: 2554-2568.

24 Hou KL, Hao MG, Bo JJ, Wang JH. CXCR7 in tumorigenesis and progression. Chin J Cancer 2010; 29: 456-459.

25 Zabel BA, Wang Y, Lewén S, Berahovich RD, Penfold ME, Zhang P et al. Elucidation of CXCR7-mediated signaling events and inhibition of CXCR4-mediated tumor cell transendothelial migration by CXCR7 ligands. J Immunol 2009; 183: 3204-3211.

26 Iwakiri S, Mino N, Takahashi T, Sonobe M, Nagai S, Okubo K et al. Higher expression of chemokine receptor CXCR7 is linked to early and metastatic recurrence in pathological stage I nonsmall cell lung cancer. Cancer 2009; 115: 2580-2593.

27 D'Alterio C, Consales C, Polimeno M, Franco R, Cindolo L, Portella L et al. Concomitant CXCR4 and CXCR7 expression predicts poor prognosis in renal cancer. Curr Cancer Drug Targets 2010; 10: 772-781.

28 Portella L, Vitale R, de Luca S, D'Alterio C, leranò C, Napolitano M et al. Preclinical development of a novel class of CXCR4 antagonist impairing solid tumors growth and metastases. PLoS One 2013; 13: 8

29 Mitra P, De A, Ethier MF, Mimori K, Kodys K, Shibuta K et al. Loss of chemokine SDF-1alpha-mediated CXCR4 signalling and receptor internalization in human hepatoma cell line HepG2. Cell Signal 2001; 13: 311-319.

30 Fedyk ER, Ryan DH, Ritterman I, Springer TA. Maturation decreases responsiveness of human bone marrow $B$ lineage cells to stromalderived factor 1 (SDF-1). J Leuk Biol 1999; 66: 667-673.

31 Honczarenko M, Douglas RS, Mathias C, Lee B, Ratajczak MZ, Silberstein LE. SDF-1 responsiveness does not correlate with
CXCR4 expression levels of developing human bone marrow B cells. Blood 1999; 94: 2990-2998.

32 Sutton A, Friand V, Brulé-Donneger S, Chaigneau T, Ziol M, SainteCatherine $\mathrm{O}$ et al. Stromal cell-derived factor-1/chemokine (C-X-C motif) ligand 12 stimulates human hepatoma cell growth, migration, and invasion. Mol Cancer Res 2007; 5: 21-33.

$33 \mathrm{Kim}$ SW, Kim HY, Song IC, Jin SA, Lee HJ, Yun HJ et al. Cytoplasmic trapping of CXCR4 in hepatocellular carcinoma cell lines. Cancer Res Treat 2008; 40: 53-61

34 Kucia M, Reca R, Miekus K, Wanzeck J, Wojakowski W, JanowskaWieczorek A et al. Trafficking of normal stem cells and metastasis of cancer stem cells involve similar mechanisms: pivotal role of the SDF1-CXCR4 axis. Stem Cells 2005; 23: 879-894.

35 Xue TC, Han D, Chen RX, Zou JH, Wang Y, Tang ZY et al. High expression of CXCR7 combined with Alpha fetoprotein in hepatocellular carcinoma correlates with extrahepatic metastasis to lung after hepatectomy. Asian Pac J Cancer Prev 2011; 12: 657-663.

36 Levoye A, Balabanian K, Baleux F, Bachelerie F, Lagane B. CXCR7 heterodimerizes with CXCR4 and regulates CXCL12-mediated G protein signaling. Blood 2009; 113: 6085-6093.

37 Rajagopal S, Kim J, Ahn S, Craig S, Lam CM, Gerard NP et al. Betaarrestin- but not G protein-mediatedsignaling by the "decoy" receptor CXCR7. Proc Natl Acad Sci USA 2010; 107: 628-632.

38 Naumann U, Cameroni E, Pruenster M, Mahabaleshwar H, Raz E, Zerwes HG et al. CXCR7 functionsas a scavenger for CXCL12 and CXCL11. PLoS One 2010; 5: e9175.

39 Boldajipour B, Mahabaleshwar H, Kardash E, Reichman-Fried M, Blaser $\mathrm{H}$, Minina $\mathrm{S}$ et al. Control of chemokine-guided cell migration by ligand sequestration. Cell 2008; 132: 463-473.

40 Luker KE, Lewin SA, Mihalko LA, Schmidt BT, Winkler JS, Coggins NL et al. Scavenging of CXCL12 by CXCR7 promotes tumor growth and metastasis of CXCR4-positive breast cancer cells. Oncogene 2012; 31: 4750-4758.

41 de Caillot FM, Kazmi MA, Lin Y, Ray-Saha S, Sakmar TP, Sachdev P. CXCR7/CXCR4 heterodimer constitutive lyrecruits beta-arrestin to enhance cell migration. J Biol Chem 2011; 286: 32188-32197.

(c) (1) (2)(2)

This work is licensed under a Creative Commons Attribution-NonCommercial-ShareAlike 3.0 Unported License. The images or other third party material in this article are included in the article's Creative Commons license, unless indicated otherwise in the credit line; if the material is not included under the Creative Commons license, users will need to obtain permission from the license holder to reproduce the material. To view a copy of this license, visit http://creativecommons.org/licenses/by-nc-sa/3.0/ 